\title{
Comparative Study on Clear Specimen Strength and Member Strength of Side-Pressure Laminated Bamboo
}

\author{
Danping Gao (D), Bowang Chen $(\mathbb{D}$, Liu Wang, Chunan Tang, and Ping Yuan \\ Department of Civil Engineering, Central South University of Forestry and Technology, Changsha, Hunan 410004, China \\ Correspondence should be addressed to Bowang Chen; 2675360783@qq.com
}

Received 26 October 2021; Revised 25 December 2021; Accepted 6 January 2022; Published 27 January 2022

Academic Editor: Piotr Smarzewski

Copyright (C) 2022 Danping Gao et al. This is an open access article distributed under the Creative Commons Attribution License, which permits unrestricted use, distribution, and reproduction in any medium, provided the original work is properly cited.

\begin{abstract}
Side-pressure laminated bamboo (LB) made from heat-modified, fast-growing bamboo is introduced in this document. As a relatively new type of bamboo composite fabricated by bamboo strips, side-pressure LB has some favorable mechanical properties, such as thermal insulation, light mass, high strength, and earthquake resistance. To promote the application of side-pressure LB in structural engineering, according to the test standards for timber, the mechanical properties of bamboo, including tensile strength parallel to the grain, compressive strength parallel to the grain, bending strength and bending modulus, and shear strength parallel to the grain, were obtained by testing clear bamboo. Meanwhile, the bending and shear tests were performed on full-sized beams of side-pressure LB. Comparing the strength of clear bamboo and full-sized bamboo beams under bending and shear, explore the effect of size on bending and shear strength. The results demonstrate that the size effect has a significant influence on the bending strength, and the bending strength decreases clearly with the increase of the span of member; the shear strength is mainly affected by the shear area and decreases with the increase of the shear area. Based on the measured indicators of shear strength, a formula suitable for converting the shear strength of clear bamboo to full-sized bamboo beam is proposed. And the recommended design strengths of bamboo are given by using the limit state method, which provides a design basis for the engineering application of bamboo.
\end{abstract}

\section{Introduction}

China is actively promoting the concept of "low-carbon sustainable development." As renewable materials fix carbon, modern industrial bamboo, with certain characteristics such as regeneration, ease of decomposition, and environmental respect, meets low-carbon and environmentally friendly development requirements. Side-pressure laminated bamboo (LB) is one of the modern industrial bamboos and is processed from crude bamboo through screening, slitting, trimming, carbonizing, selecting pieces, sizing, assembling, hot pressing, and so on. Nation and foreign researchers have discussed the perspective of applying LB in the field of civil engineering through much research into its mechanical properties. Jiang et al. [1], Zhang et al. [2], and Madhavi et al. [3] found that the tensile, compressive, bending, and shear strength and elastic modulus of LB composites are higher than those of wood. Su et al. [4] analyzed the nonlinear mechanical behavior and failure modes of $15 \mathrm{LB}$ beams and gave the analysis and calculation model of those beams under bending. Considering both the slenderness ratio and the eccentricity ratio factors, $\mathrm{Li}$ et al. [5] investigated the performances of LB short columns under axial compression and eccentric compression and gave a fine stress-strain model under compression. Chen et al. [6] examined the failure modes and constitutive relationship of structural LB under tension and compression. Tang et al. [7] conducted long-term compression tests on three groups of side-pressed LB prismatic specimens with different stress ratios, introducing that the deformation of specimens can be divided into two stages: transient and steady-state creep, and the creep cannot tend to be stable when the stress level exceeds 0.4 times.

The above researches have indicated that $\mathrm{LB}$ can be used as a building material, with great application potential. However, the existing researches only focus on the 
mechanical properties and failure modes of clear specimens or those of full-sized members of LB, and few scholars analyze the relationship between the clear bamboo strength and the member strength. Although the industrially processed bamboo can meet the demands of structural members for mechanical properties, durability, large section, and long span, there are great differences in size, working condition, and loading time (the design benchmark period for timber structures is 50 years) before and after bamboo is processed. The basic mechanical properties of clear specimens measured in the laboratory cannot completely replace those of members in large-scale projects. In addition, the application of LB is limited by the lack of representative test methods and design strengths in China. Considering these issues, the authors of this paper carried out experimental research on the clear bamboo and full-sized beams of side-pressed LB, compared the compressive strength and bending strength of the two specimens, and analyzed the laws of their changes with size. And the limit state method was used to give the design strengths of side-pressed LB, which provide a design basis for the application of bamboo in the field of building structures.

\section{Mechanical Property Test of the Small Clear Specimen}

The physical and mechanical properties tests include testing tensile strength parallel to the grain, compressive strength parallel to the grain, shear strength parallel to the grain, bending strength, and bending modulus.

2.1. Clear Specimen Design. The bamboo selected in the tests is Phyllostachys pubescens, with a density of $640 \mathrm{~kg} / \mathrm{m}^{3}$ and a moisture content of $6.3 \%$. The clear specimens are selected and manufactured by GB/T 36872-2018 Code of Glued Laminated Timber Production [8]. Referring to the variation coefficient of strength of wood given in the Manual for Design of Timber Structures [9], combined with GB/T 1929-2009 Method of Sample Logs Sawing and Test Specimens Selection for Physical and Mechanical Tests of Wood [10], according to the confidence level of 0.95 and the minimum specimens required when the accuracy index $p=5 \%$, determine the number of specimens for tension, compression, bending, and shear tests to be $32,16,32$, and 20 , respectively.

2.2. Tensile and Compressive Strength Parallel to the Grain. According to GB/T 1938-2009 Method of Testing in Tensile Strength Parallel to Grain of Wood [11] and GB/T 1935-2009 Method of Testing in Compressive Strength Parallel to Grain of Wood [12], the uniaxial tension and compression tests are carried out on clear bamboo. The size of tensile specimens is shown in Figure 1. The size of compressive specimens is 30 by 20 by $20 \mathrm{~mm}$. Figure 2 presents the field of strength test. Terminally, the tensile failure indicates brittle properties, and the deformation of clear bamboo shows certain plasticity under compression.

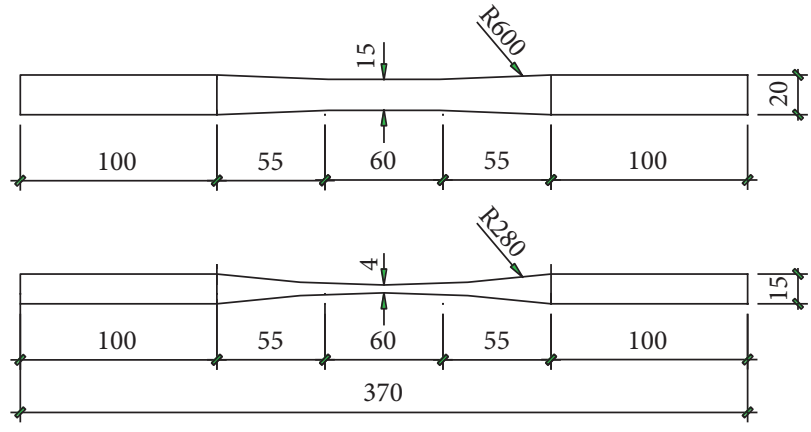

FIgURE 1: Size of tensile specimen parallel to the grain.

2.3. Bending Strength and Bending Modulus. According to GB/T 1936.1-2009 Method of Testing in Bending Strength of Wood [13] and GB/T 1936.2-2009 Method for Determination of The Modulus of Elasticity in Static Bending of Wood [14], the size of bending specimens is 300 by 20 by $20 \mathrm{~mm}$, and it undergoes two different loading methods. The specimens for measuring bending strength adopt a one-point loading method. And by using a two-point loading configuration, the tests of bending modulus are performed, as shown in Figure 3. Finally, the bending failure presents that the bottom fiber of the specimens rupture at the midspan, and the failure mode is shown in Figure 4.

2.4. Shear Strength Parallel to the Grain. The tests are conducted about GB/T 1928-2009 Test Methods for Physical and Mechanical Properties of Wood [15]. See Figure 5 for the size of test specimens and Figure 6 for the test device.

Table 1 summarizes the results of the above-mentioned mechanical properties tests of clear specimens of sidepressure LB.

\section{Design Strength}

GB 50068-2018 Unified Standard for Reliability Design of Building Structure [16] stipulated that the design method of building structures should adopt the limit state method based on probability theory and expressed by partial coefficients. It is necessary to analyze the reliability of members when determining the design strength, which is related to the effect of action $S$ and structural resistance $R$, in which $R$ is mainly affected by the variability of the strength of a material. The partial coefficients of resistance under each stress state given in Manual for Design of Timber Structures [9] are all empirical values. Moreover, the variability of strength of wood fluctuates widely, and its coefficient of variation is usually between 0.05 and 0.50 , while the range of side-pressure LB is around 0.10 from the results of the clear bamboo tests. There will be a deviation if the partial coefficients of resistance for wood directly are used to study the reliability of LB. Still, the variability of strength of side-pressure LB is small, and there are many similarities between bamboo and wood in material properties, processing, and testing. Therefore, the partial coefficients of resistance for side-pressure LB can be 


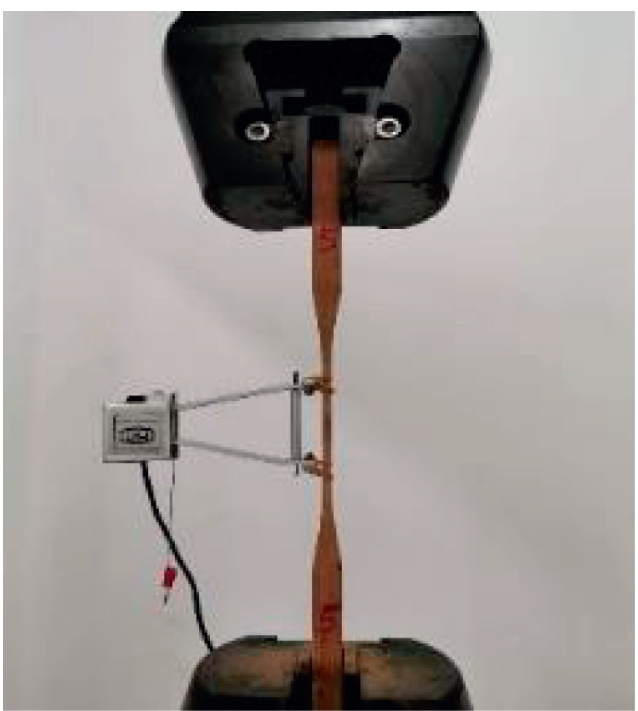

(a)

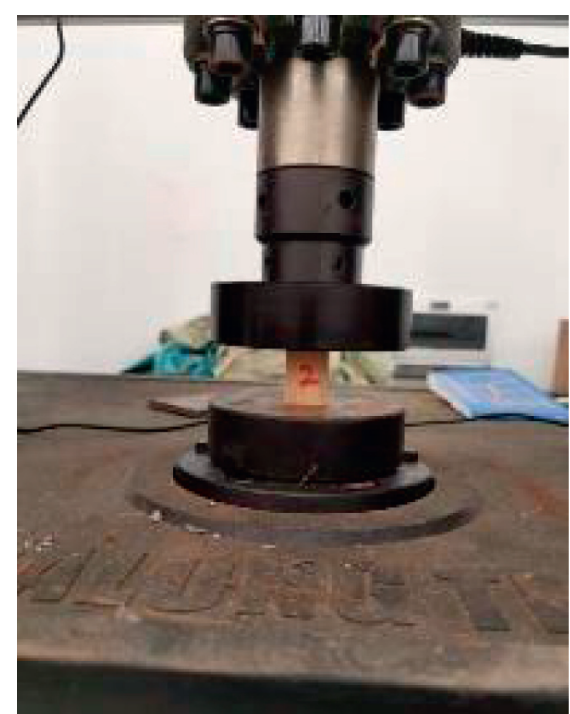

(b)

Figure 2: Testing field. (a) Tension test. (b) Compression test.

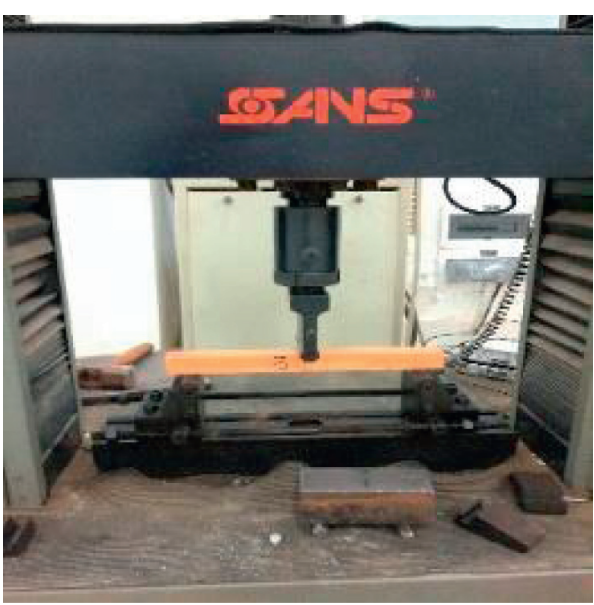

(a)

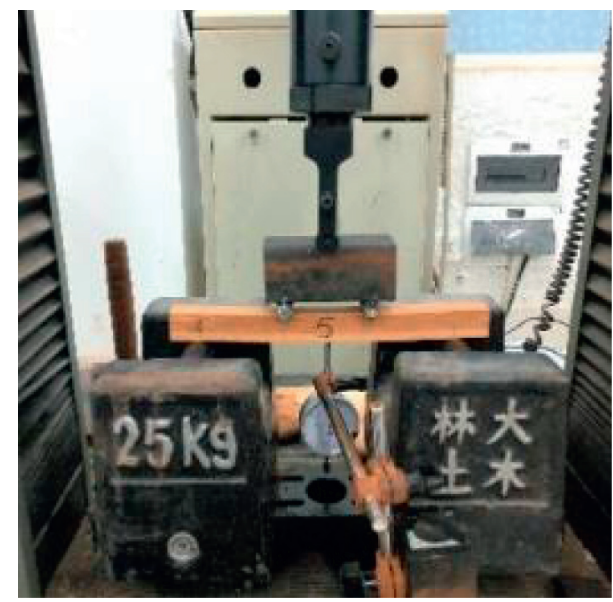

(b)

Figure 3: Apparatus testing in bending. (a) Apparatus testing in bending strength. (b) Apparatus testing in bending modulus.

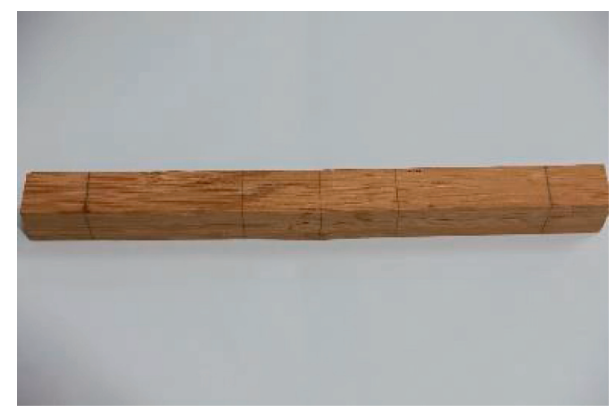

FIgURE 4: Failure mode of bending specimen.

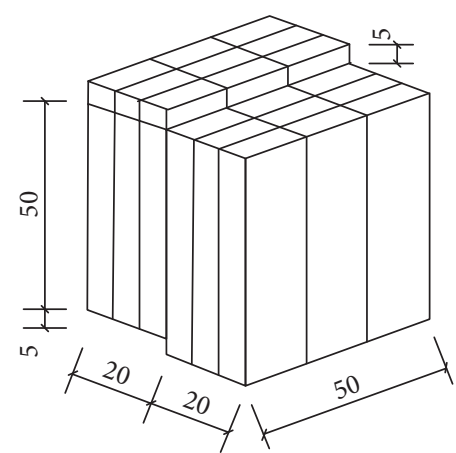

Figure 5: Size of shear specimen. determined concerning the analytical method for the reliability of timber structure and then determine its design strength.
The performance function when the structure is in the limit state is $Z=(R, S)=R-S=0$, whose expression after considering various randomness is as follows: 


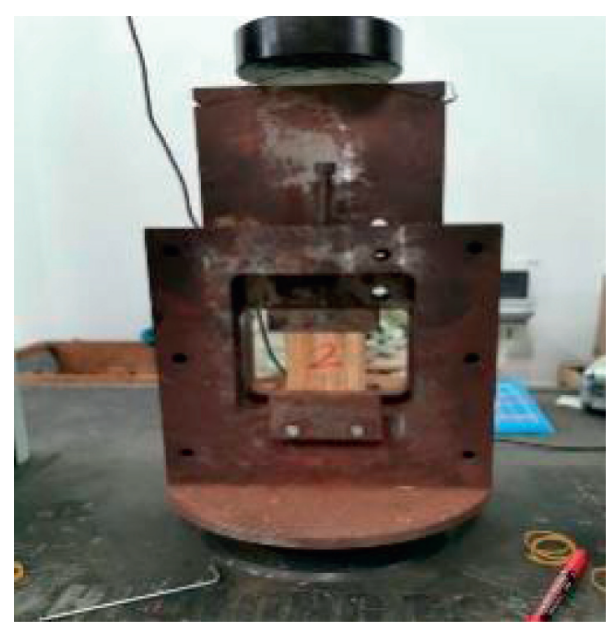

Figure 6: Device for shear test.

TABLE 1: Summary of basic material properties.

\begin{tabular}{|c|c|c|c|c|c|}
\hline Strength type & Maximum (MPa) & Minimum (MPa) & Average $(\mathrm{MPa})$ & Standard deviation $(\mathrm{MPa})$ & $\begin{array}{c}\text { Coefficient of } \\
\text { variation }\end{array}$ \\
\hline Compressive strength parallel to grain & 90.3 & 64.9 & 84.9 & 3.04 & 0.04 \\
\hline Tensile strength parallel to grain & 143.0 & 87.9 & 111.7 & 16.5 & 0.15 \\
\hline Tensile modulus & 10844.6 & 7107.3 & 9194.4 & 1101.1 & 0.12 \\
\hline Bending strength & 130.0 & 96.2 & 111.9 & 8.2 & 0.07 \\
\hline Bending modulus & 13842.4 & 8515.0 & 11622.8 & 349.2 & 0.03 \\
\hline Shear strength parallel to grain & 13.8 & 10.6 & 12.1 & 1.1 & 0.09 \\
\hline
\end{tabular}

$$
Z=K_{A} K_{P} K_{\mathrm{Q} 3} f-\frac{f_{k} K_{\mathrm{DOL}}(g+q \rho) K_{B}}{\gamma_{R}\left(\gamma_{G}+\psi_{C} \gamma_{\mathrm{Q}} \rho\right)},
$$

where $K_{A}$ =geometry deviation caused by the difference between actual size and design size of members; $K_{P}=$ coefficient of uncertainty (deviation) calculated for resistance; $K_{Q 3}=$ coefficient of load duration; $f=$ short-term strength of wood; $f_{k}=$ characteristic strength with $95 \%$ guarantee rate; $K_{\mathrm{DOL}}=$ coefficient of persistent load effect; $g=G / G_{k}$, represents the ratio of the permanent load to its characteristic value; $q=Q / Q_{k}$, represents the ratio of the variable load to its characteristic value; $\rho=Q_{k} / G_{k}$, represents the ratio of the characteristic value of the variable load to that of the permanent load; $K_{B}=$ coefficient of uncertainty of load effect; $\gamma_{R}=$ partial coefficient of resistance; $\gamma_{G}=$ partial coefficient of permanent load; $\gamma_{Q}=$ partial coefficient of variable load; and $\psi_{C}=$ coefficient of combination value of variable load.

Zhu et al. [17] analyzed the reliability of tensile, compressive, and bending members under four load combinations and obtained the relationship curves between the partial coefficient of resistance and the coefficient of strength variation that meets the reliability requirements. It is recommended to select the relationship curves between the partial coefficient of resistance and the coefficient of strength variation when $\rho=1$ under the load combination consisting of a variable load on the residential floor with the permanent load as the benchmark curves for determining the design strength. And the curves are shown in Figure 7. According to

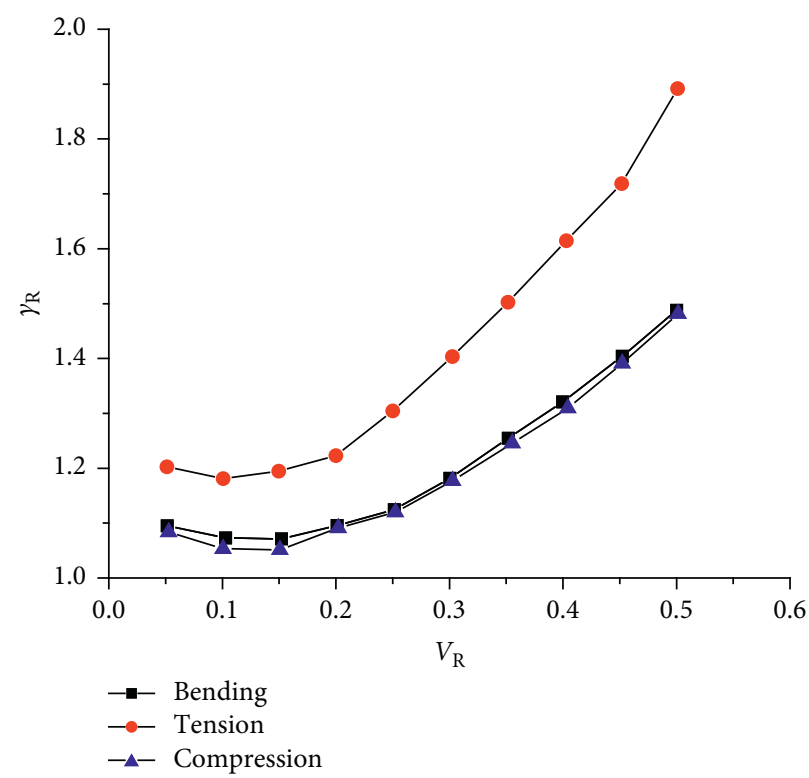

FIgURE 7: Benchmark curves.

the failure modes of clear bamboo, the tensile and shear failure are brittle, while the bending and compressive failure are ductile. For general buildings with a design reference period of 50 years and a safety level of class II, the target reliability index $\beta_{0}$ of tension, compression, bending, and shear are 3.7, 3.2, 3.2, and 3.7, respectively. And the determination of the partial coefficient of resistance for shear 
can refer to the benchmark curve of tensile failure. Therefore, the partial coefficient of resistance $\gamma_{R}$ for tension, compression, bending, and shear, respectively, are 1.21, 1.07, 1.07, and 1.18.

The calculation formula of the design strength for a single material is

$$
f_{d}=\frac{K_{\mathrm{DOL}} f_{k}}{\gamma_{R}},
$$

where $f_{d}=$ design strength, $\gamma_{R}=$ partial coefficient of resistance, and $K_{\mathrm{DOL}}=$ coefficient of persistent load effect; take 0.72 refer to $G B$ 50005-2017 [18].

Considering some factors such as reliability index, variation coefficient of strength, and effect of size, He et al. [19] further adjusted equation (2) when calculating the design strength of the modified scrimber to obtain

$$
f_{d}=\frac{K_{\mathrm{Q} 1} K_{\mathrm{Q} 2} K_{\mathrm{Q} 3} f_{k}}{\gamma_{R} K_{d}},
$$

where $K_{Q 1}=$ coefficient of strength adjustment under permanent load; take $0.80, K_{\mathrm{Q} 2}=$ coefficient of baseline adjustment meeting the reliability requirements, $K_{Q 3}=$ coefficient of load duration; take 0.72 , and $K_{d}=$ coefficient of safety considering the effect of size; take 1.20 .

Considering the difference in production technology between LB and modified scrimber, the coefficient of natural defects $K_{Q 4}$ and coefficient of drying defects $K_{Q 5}$ need to be introduced to correct equation (3) when calculating the design strengths of LB. Refer to the research on glubam by Xiao et al. [20], $K_{\mathrm{Q} 4}$ and $K_{\mathrm{Q} 5}$ for wood are multiplied by coefficients 1.2 and 1.1, respectively. The adjusted values are shown in Table 2.

Note: the values in brackets represent the coefficient of natural defects and coefficient of drying defects before adjustment.

Modify equation (3) to obtain equation (4), as follows:

$$
f_{d}=\frac{K_{\mathrm{Q} 1} K_{\mathrm{Q} 2} K_{\mathrm{Q} 3} K_{\mathrm{Q} 4} K_{\mathrm{Q} 5} f_{k}}{\gamma_{R} K_{d}} .
$$

Take the fractile corresponding to the normal distribution percentage $p=0.05$ as the characteristic strength of clear specimens, calculated by the following equation:

$$
f_{k}=\mu_{f}-1.645 \sigma_{f}
$$

where $\mu_{f}=$ average strength and $\sigma_{f}=$ standard deviation of strength.

Considering that the strength of clear wood is affected by moisture content, GB/T 1928-2009 Test Methods for Physical and Mechanical Properties of Wood [15] stipulates that the strength of clear wood is based on that when the moisture content is $12 \%$. The tensile, compressive, bending, and shear resistance of wood can be converted from the strength when the moisture content of the specimen is $\omega \%$ to that when the moisture content is $12 \%$ to the following equation:

$$
f_{k}^{\prime}=f_{k}[1+\alpha(\omega-12)]
$$

where $f_{k}^{\prime}=$ characteristic strength of specimen when moisture content is $12 \%$ and $\alpha=$ coefficient of moisture content conversion, taken as 0.015 for the tensile strength along the grain, is 0.050 for the compressive strength along the grain, is 0.040 for the bending strength, and is 0.030 for the shear strength along the grain.

In summary, the calculation formula for design strength of side-pressure LB is

$$
f_{d}=\frac{K_{\mathrm{Q} 1} K_{\mathrm{Q} 2} K_{\mathrm{Q} 3} K_{\mathrm{Q} 4} K_{\mathrm{Q} 5} f_{k}^{\prime}}{\gamma_{R} K_{d}} .
$$

Comparing the design strengths of side-pressure LB calculated by equation (7) with those of some structural materials such as log and composite lumber, the results are shown in Table 3. According to the comparison, the strength indexes of side-pressure LB are higher than other materials, indicating that side-pressure LB has good mechanical properties and can be used in structural engineering.

\section{Mechanical Property Test of Full-Sized Member}

To further verify the rationality of the design indexes of sidepressure LB and explore the influence of size effect on its bending and shear strength, the bending tests and shear tests of full-sized bamboo beams are conducted.

4.1. Full-Sized Member Design. The full-sized bamboo beams and clear bamboo are in one batch. The size of full-sized beams is designed referring to GB/T 50329-2012 Standard for Test Methods of Timber Structures [21]. The bending tests concerned several factors such as span-to-height ratio, height-to-width ratio, and loading method, accordingly, four groups of members were designed, with two in each group. The shear tests takes shear-to-span ratio as the impact factor, and two sets of beams are designed, two in each set. And the parameters of the beams are shown in Table 4. It should be noted that the size of the beam in this paper is not strictly full-scale, generally only a rather semitechnical scale because it is hard to achieve full-sized members in the laboratory.

4.2. Bending Test. Two groups of beams A and B, with a span-to-height ratio of 17 , are loaded at two-point monotonic configuration points, and the loading diagram is shown in Figure 8. The one-point loading method is carried out in two groups of beams $\mathrm{C}$ and $\mathrm{D}$, with a span-to-height ratio of 8.33 , and a schematic of the device as shown in Figure 9. Both ends of the members are hinged, and three dial indicators are arranged at the midspan and both ends. At the midspan, five strain gauges are pasted at equal distances along with the height of the section to obtain the change rules of midspan cross section strain with height under loading. The bending test uses a step-by-step loading, and the load gradually increases at a loading rate of $2 \mathrm{kN}$ until beam is damaged, or the load drops to $80 \%$ of the ultimate. 
TABLE 2: The adjustment coefficient of natural defect and coefficient of dry defect.

\begin{tabular}{lcccc}
\hline Type & Tension parallel to grain & Compression parallel to grain & Bending & Shear parallel to grain \\
\hline$K_{Q 4}$ & $0.79(0.66)$ & $0.96(0.80)$ & $0.90(0.75)$ & - \\
$K_{Q 5}$ & $0.99(0.90)$ & - & $0.94(0.85)$ & $0.90(0.82)$ \\
\hline
\end{tabular}

TABLE 3: Comparison of design strengths between side-pressure LB and structural materials.

\begin{tabular}{lccccc}
\hline \multirow{2}{*}{ Materials } & \multicolumn{4}{c}{ Design strength } & \\
& Tension (MPa) & Compression (MPa) & Bending (MPa) & Shear (MPa) & \multirow{2}{*}{ Modulus of elasticity (MPa) } \\
\hline Larix spp. principis-Rupprechtii & 9.5 & 15 & 17 & 1.6 & 10000 \\
Larix spp. sibirica & 8.5 & 12 & 13 & 1.5 & 10000 \\
Pseudotsuga spp. LVL & 8.5 & 14.5 & 14.7 & 2.0 & 11000 \\
Pseudotsuga spp. PSL & 13.4 & 17.2 & 17.2 & 1.6 & 12400 \\
Side-pressure LB & 20.0 & 18.1 & 21.3 & 2.5 & 9200 \\
\hline
\end{tabular}

TABLE 4: Size of full-sized beams.

\begin{tabular}{|c|c|c|c|c|c|}
\hline Test & Beam number & Size of beam $(\mathrm{mm})$ & Effective span (mm) & Span-to-height ratio & Loading method \\
\hline \multirow{4}{*}{ Bending test } & $\mathrm{A} 1, \mathrm{~A} 2$ & $60 \times 120 \times 2300$ & 2040 & 17 & \multirow{2}{*}{ Two-point loading } \\
\hline & $\mathrm{B} 1, \mathrm{~B} 2$ & $80 \times 120 \times 2300$ & 2040 & 17 & \\
\hline & $\mathrm{C} 1, \mathrm{C} 2$, & $60 \times 120 \times 1150$ & 1000 & 8.33 & \multirow{4}{*}{ One-point loading } \\
\hline & $\mathrm{D} 1, \mathrm{D} 2$ & $80 \times 120 \times 1150$ & 1000 & 8.33 & \\
\hline \multirow{2}{*}{ Shear test } & E1, E2, & $60 \times 120 \times 720$ & 480 & 4 & \\
\hline & $\mathrm{F} 1, \mathrm{~F} 2$ & $60 \times 120 \times 720$ & 600 & 5 & \\
\hline
\end{tabular}

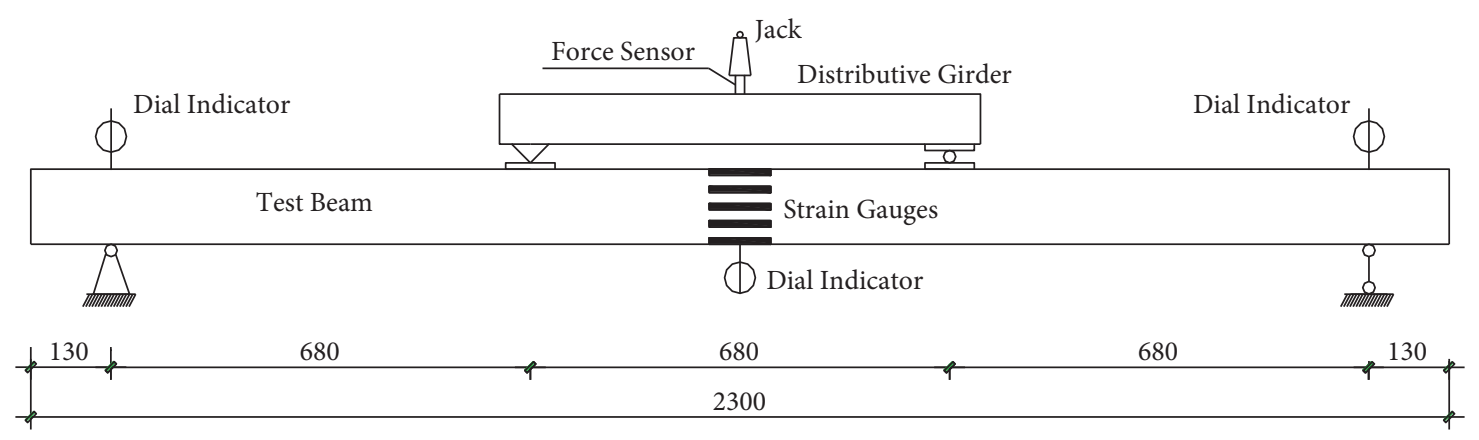

FIGURE 8: Diagram of two-point loading configuration.

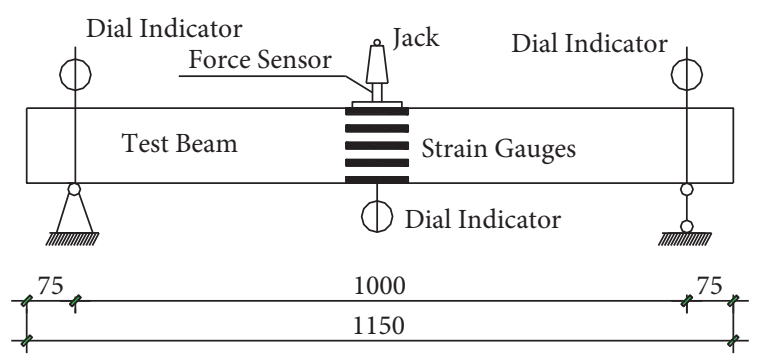

FIGURE 9: Diagram of one-point loading configuration.

4.3. Shear Test. The members are divided into groups $\mathrm{E}$ and $\mathrm{F}$. The shear-to-span ratio of group $\mathrm{E}$ is 2.0 , and group $\mathrm{F}$ is 2.5. Both ends of beams are hinged, and the test device is shown in Figure 10. The shear test used a step loading by using a jack, and the load gradually increases at a loading rate of $3 \mathrm{kN}$ until members are destroyed.

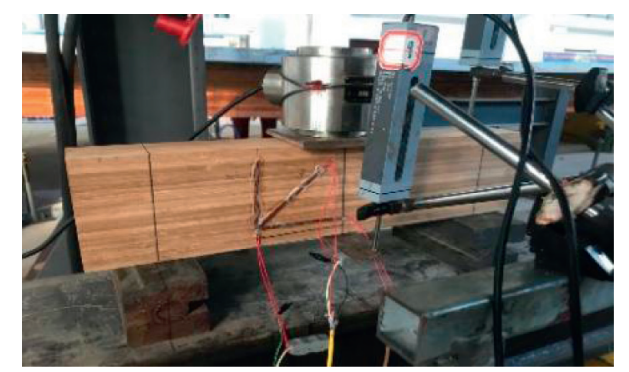

FIgURE 10: Shear test device for full-size beams.

\section{Result and Analysis of Full-Sized Member Test}

5.1. Failure Mode. In general, the failure modes of full-sized bamboo beams are mainly as follows: the bottom fiber tear at midspan of beam, bottom fiber tear at non-midspan of 
beam, horizontal tearing or adhesive layer cracking, local fiber of the top layer is crushed, excessive midspan deflection, and out-of-plane instability under bending moment.

In bending test, the beams of groups A and B have no obvious damage during loading while the deflection is so large that the beam looks like a "curved bow." Considering that member will lose value in engineering applications if its deformation is too large, hence the loading stops when the midspan deflection of beam reaches $70 \mathrm{~mm}\left(l_{0} / 29\right)$. After unloading, the instantaneous recovery of deflection accounts for $65 \%-85 \%$ of the maximum deformation, which indicates good toughness and recovery ability. The failure mode is presented in Figure 11(a). The failure of groups C and D beams are mainly caused by excessive tension of the bottom fiber at the midspan of beams. However, the individual beam such as D2 has some defects such as bamboo joints, cracks on its bottom, resulting in a local stress concentration, namely, notch effect, which makes the bottom fiber be pulled off at the non-midspan of beam. The final failure mode is shown in Figure 11(b). In shear tests, the failure mode of member is that the horizontal cracks parallel to the grain develop on both ends of the beam, and the failure is brittle without an obvious sign, as shown in Figure 12.

5.2. Load-Displacement Curve. Figure 13 shows the comparison between load-displacement curves for the full-sized beams under bending and shear. It explains that the beams have significant nonlinear characteristics. Groups of A and B beams stopped loading due to excessive deflection, and no damage occurred. The other beams have experienced the elastic deformation stage, elastic-plastic deformation stage, and failure stage.

5.3. Calculation for Bending Modulus of Elasticity. GB/T 50329-2012 Standard for Test Methods of Timber Structures [21] stipulates that the span-to-height ratio of bending beams should be 18 . For the beams with an 8.33 span-toheight ratio in the bending test, the shear deformation will cause additional deflection, so the influence of shear deformation needs to be considered when calculating the bending modulus of elasticity. Equation (8) shows the classical theory about deflection of beam in mechanics of materials. Integrating equation (8) to obtain the calculation formula for shear deformation, as follows gives equation (9):

$$
\begin{aligned}
\frac{\mathrm{d} \omega_{v}}{\mathrm{~d}_{x}} & =\gamma_{c}=\frac{\alpha_{s} V}{\mathrm{GA}}, \\
\omega_{v} & =\int_{0}^{l_{0} / 2} \frac{\alpha_{s} V}{\mathrm{GA}} \mathrm{d}_{x}=\frac{3 \mathrm{Fl}_{0}}{8 \mathrm{GA}},
\end{aligned}
$$

where $\omega_{v}=$ shear deflection, $\gamma_{c}=$ shear strain, $\alpha_{s}=$ shear coefficient; take 1.5 for rectangular section, $V=$ shear capacity, $\mathrm{GA}=$ shear stiffness, and

$l_{0}=$ effective span.

The total deflection is the sum of the bending deflection $\omega_{f}$ and the shear deflection $\omega_{v}$, calculated by the following equation:

$$
\omega=\omega_{f}+\omega_{v}=\frac{\mathrm{Fl}_{0}^{3}}{48 E_{b} I}+\frac{3 \mathrm{Fl}_{0}}{8 \mathrm{GA}} .
$$

Note that $E_{b}$ represents the bending modulus of elasticity, calculated by the following equation:

$$
E_{b}=\frac{23 \Delta \mathrm{Fl}_{0}^{3}}{108 b h^{3} \Delta \omega},
$$

where $\Delta \mathrm{F}=$ difference between the upper and lower limit loads, $b=$ width of cross section, $h=$ height of cross section, and

$\Delta \omega=$ difference the displacement corresponding to the upper and lower limit loads.

Design Principle of Timber Structures [22] stipulates that the members used to test the bending strength shall undergo two-point loading. When using a one-point loading method, the influence of the span-to-height ratio of full-sized members and load-distributing mode should be considered, and the bending modulus of elasticity should be adjusted according to the following equation:

$$
\frac{E_{2}}{E_{1}}=\frac{1+k_{1}\left(h_{1} / L_{1}\right)^{2}(E / G)}{1+k_{2}\left(h_{2} / L_{2}\right)^{2}(E / G)},
$$

where $E_{1}=$ bending modulus of elasticity corresponding to height-to-span ratio $h_{1} / L_{1}, E_{2}$ = bending modulus of elasticity corresponding to height-to-span ratio $h_{2} / L_{2}$, $E / G=$ ratio of bending modulus to shear modulus; take 6.8 for parallel to the grain of $\mathrm{LB}$, and $k_{i}=$ coefficient of loaddistributing mode; take 1.20 for the one-point loading method and 0.939 for the two-point loading method.

Calculated by equation (12), the bending modulus of elasticity of the member with a span-to-height ratio of 17 under two-point loading is 1.09 times that of the member with a span-to-height ratio of 8.33 under one-point loading, and the measured value in bending test is 1.12 times. The theoretical value is close to the measured value, and the results are shown in Table 5. Compared with the values in Table 1, the average of the bending modulus of elasticity of full-sized members is $8831 \mathrm{MPa}$, which is $77 \%$ of clear bamboo.

Note. The values in parentheses represent the bending modulus elasticity and bending strength after adjustment.

5.4. Effect of Size. The size effect is also called the volume effect, which can be explained by the weakest chain theory, which means that as the volume increases, the probability of defects in the member is higher, and its strength will decrease, especially the strength of members with a brittle failure mode. Usually, the bending failure is caused by the fracture of the bottom bamboo fibers, and the differences in bending strength are mainly controlled by length of member, so the weakest chain theory is suitable for bamboo under bending. However, bamboo has a long yield platform and good ductility when it is compressed; greater problem about accuracy will occur if the weakest chain theory is used to describe the size effect of bamboo when compressed. Given this, GB 50005-2017 Standard for Design of Timber 


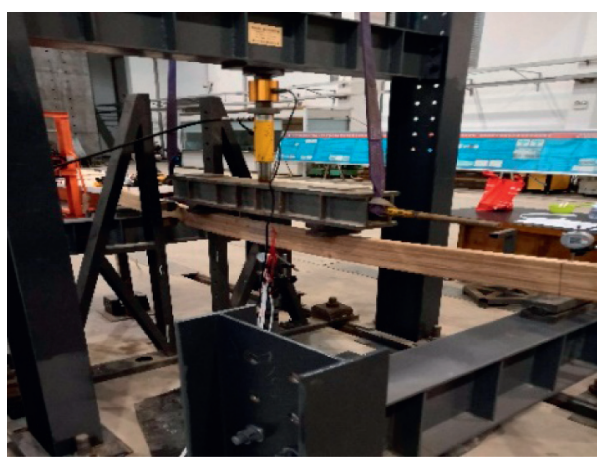

(a)

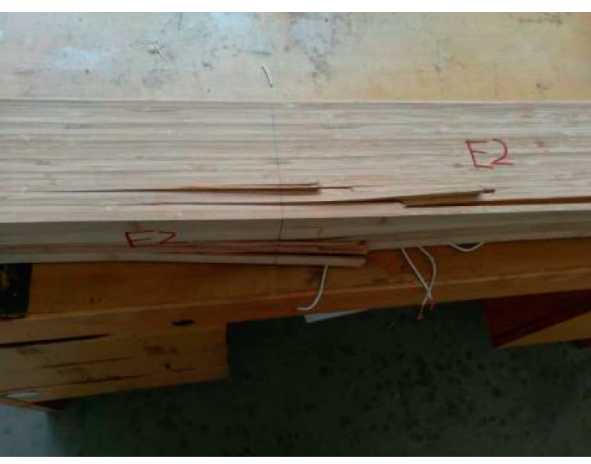

(b)

FIgURE 11: Failure mode of bending beam. (a) Groups A and B. (b) Group C and D.

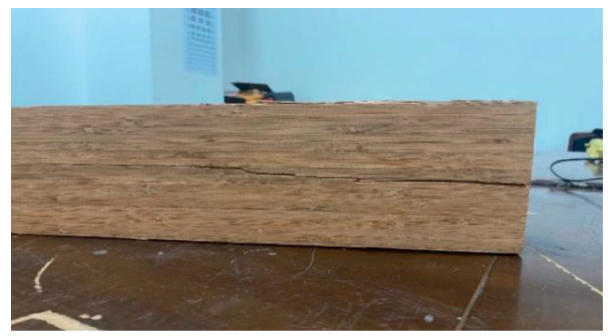

FIGURE 12: Failure mode of shear beam.

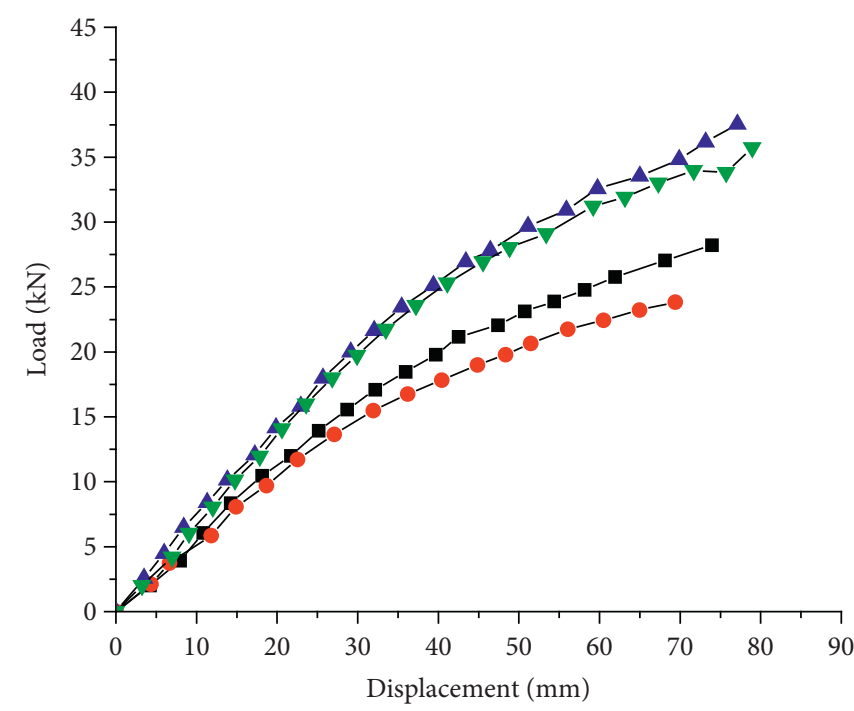

$\rightarrow-\mathrm{A} 1$
$\rightarrow-B 1$
$\rightarrow-B 2$

(a)

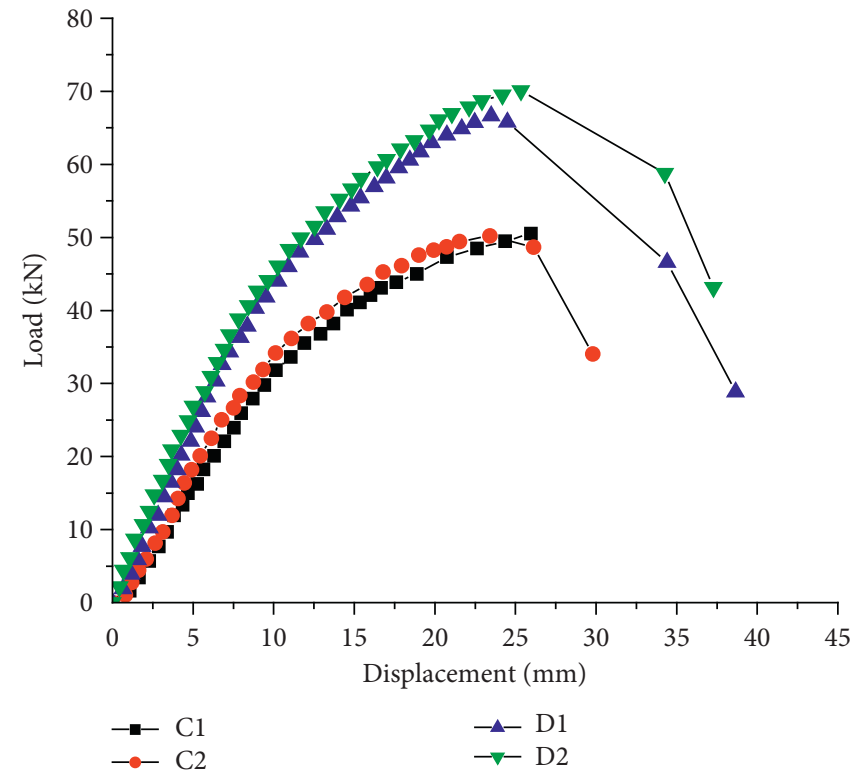

(b)

FIgURE 13: Continued. 


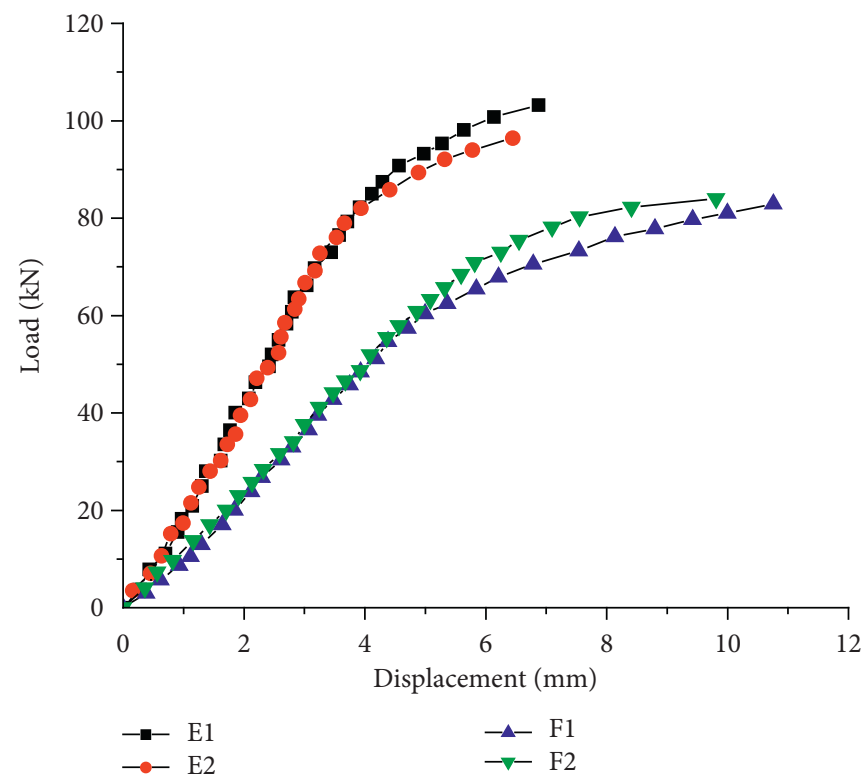

(c)

Figure 13: Load-displacement curves. (a) Groups A and B. (b) Groups C and D. (c) Groups E and F.

TABLE 5: The test results of the full-sized members in bending.

\begin{tabular}{lccccc}
\hline $\begin{array}{l}\text { Beam } \\
\text { number }\end{array}$ & $\begin{array}{c}\text { Span-to-height } \\
\text { ratio }\end{array}$ & $\begin{array}{c}\text { Bending modulus elasticity } \\
E_{b} / \mathrm{MPa}\end{array}$ & $\begin{array}{c}\text { Midspan deflection } \\
\omega_{u} / \mathrm{mm}\end{array}$ & $\begin{array}{c}\text { Ultimate load } \\
F_{u} / \mathrm{kN}\end{array}$ & $\begin{array}{c}\text { Ultimate bending strength } \\
f_{u} / \mathrm{MPa}\end{array}$ \\
\hline A1 & 17 & 9630 & 70.00 & 27.40 & 64.70 \\
A2 & 17 & 9149 & 70.00 & 24.10 & 56.90 \\
B1 & 17 & 9193 & 70.00 & 34.90 & 61.80 \\
B2 & 17 & 8872 & 70.00 & 33.90 & 60.00 \\
C1 & 8.33 & $7905(8835)$ & 25.50 & 50.20 & $87.15(71.43)$ \\
C2 & 8.33 & $8301(8393)$ & 23.81 & 50.00 & $86.81(71.16)$ \\
D1 & 8.33 & $8359(8434)$ & 39.89 & 66.50 & $86.59(70.98)$ \\
D2 & 8.33 & $8480(8139)$ & 25.89 & 69.90 & $91.02(74.61)$ \\
\hline
\end{tabular}

Structures [18] gives an adjustment coefficient of 1.00 when dealing with the effect of size on compressive strength.

5.4.1. Bending Strength. It is necessary to consider the influence of the load-distributing mode on the strength of bamboo when calculating bending strength. The fuller the shape of the bending moment figure is, the lower the bending strength is, which is consistent with the conclusion obtained by using two loading methods in bending test. The coefficient of strength adjustment of members under two-point loading and one-point loading is 1.00 and 1.22 , respectively. Table 5 shows the adjusted bending strengths.

ASTM D1990-16 Standard Practice for Establishing Allowable Properties for Visually Graded Dimension Lumber from In-Grade Tests of Full-Size Specimens [23] gives the adjusted formula for the size effect of different volumes of wood, as follows:

$$
\frac{\sigma_{2}}{\sigma_{1}}=\left(\frac{h_{1}}{h_{2}}\right)^{k_{h}}\left(\frac{B_{1}}{B_{2}}\right)^{k_{B}}\left(\frac{L_{1}}{L_{2}}\right)^{k_{L}},
$$

where $\sigma_{i}=$ strength corresponding to different volumes of wood, $k_{h}=$ shape parameter of height $h, k_{B}=$ shape parameter of width $B$; take 0 , and

$k_{L}=$ shape parameter of length $L$.

For bending member, the influence of the change in section width is generally ignored, but the span-to-height ratio $\beta_{i}$ needs to be adjusted. After adjustment, the following equation is obtained:

$$
\frac{\sigma_{2}}{\sigma_{1}}=\left(\frac{h_{1}}{h_{2}}\right)^{k_{h}}\left(\frac{\beta_{1} h_{1}}{\beta_{2} h_{2}}\right)^{k_{L}} .
$$

If the height of beams with different lengths are equal $\left(h_{1}=h_{2}\right)$, equation (14) can be written as

$$
\frac{\sigma_{2}}{\sigma_{1}}=\left(\frac{\beta_{1}}{\beta_{2}}\right)^{k_{L}} \text {. }
$$

Take the logarithm on both sides of equation (15) to obtain

$$
k_{L}=-\frac{\ln \sigma_{1}-\ln \sigma_{2}}{\ln \beta_{1}-\ln \beta_{2}} .
$$


TABle 6: The test results of the full-sized members in shear.

\begin{tabular}{lccccc}
\hline $\begin{array}{l}\text { Beam } \\
\text { number }\end{array}$ & $\begin{array}{c}\text { Shear-to-span } \\
\text { ratio }\end{array}$ & $\begin{array}{c}\text { Midspan deflection } \\
\omega_{u} / \mathrm{mm}\end{array}$ & $\begin{array}{c}\text { Ultimate load } \\
F_{v} / \mathrm{kN}\end{array}$ & $\begin{array}{c}\text { Ultimate shear strength } \\
f_{v} / \mathrm{MPa}\end{array}$ & $\begin{array}{c}\text { Calculated value of shear } \\
\text { strength/MPa }\end{array}$ \\
\hline E1 & 2.0 & 7.1 & 102.8 & 10.71 & $\begin{array}{c}\text { Error } \\
\%\end{array}$ \\
E2 & 2.0 & 6.6 & 96.4 & 10.00 & 9.35 \\
F1 & 2.5 & 11 & 82.9 & 8.64 & 9.35 \\
F2 & 2.5 & 10 & 84.2 & 8.77 & 9.35 \\
\hline
\end{tabular}

According to equation (16), the average of $k_{L}$ for sidepressed LB is 0.23 , which is less than for wood under bending, which is 0.29 . Equation (15) indicates that the bending strength will decrease with the increase of length of beam under the same loading method and section height. Combined with Table 1, after considering the effect of the load distribution model, the effective span of bamboo beam is increased by $104 \%$, and the bending strength is reduced by $15.5 \%$. The bending strength of clear bamboo is 1.55 times that of the beam with the effective span of $1 \mathrm{~m}$ and 1.84 times that of the beam with the effective span of $2.04 \mathrm{~m}$. The result illustrates that its bending strength decreases significantly with the span of the beam increase.

5.4.2. Shear Strength. Table 6 summarizes the test results of the full-sized members in shear. Under the same size, the larger the shear-to-span ratio is, the smaller the shear strength is. Compared with the data in Table 1, the shear strength of the clear bamboo is 1.27 times that of the fullsized beams, indicating that the size effect has a certain influence on the shear strength. Foreign scholars $[24,25]$ found that the key to the size effect on shear strength lies in the shear area, which has a power function relationship with shear strength. The shear strength decreases with the increase of shear area and will be further reduced when there are bamboo nodes on the shear section. Rammer and Soltis [26] proposed an empirical formula for the conversion of shear strength between the laminated timber beams and clear wood:

$$
\tau=\frac{1.3 K_{f} \tau_{\mathrm{ASTM}}}{A^{1 / 5}},
$$

where $\tau=$ shear strength of beam, $1.3=$ coefficient of shear area adjustment of clear specimen, $K_{f}=$ coefficient of stress concentration; take 2.0,

$\tau_{\mathrm{ASTM}}=$ shear strength of clear specimen in ASTM D14314 [27], and $A=$ shear area.

Refer to equation (17) for the calculation of the shear strengths of the full-sized beams of side-pressure LB, and the errors are around 10\% (see Table 6).

\section{Conclusion}

(1) Side-pressure LB is a promising green construction material with high strength and stable mechanical properties. It shows excellent ductility under compression and bending, while its failure mode is brittle when subject to tension and shear, which should be paid attention to in actual engineering.

(2) Refer to the theory of reliability of timber structure to determine the partial coefficients of resistance for side-pressure LB, and use the limit state method to give the design strengths of side-pressure LB. And compared with several frequently used timbers in engineering, the design strengths of side-pressure LB are much higher than those of them.

(3) Comparing the strength of the clear bamboo and the full-sized bamboo beams under bending and shear, it is found that the size effect has a more significant impact on the bending strength, and the bending modulus of elasticity is also affected by the size effect.

(4) The members used in the full-size test are not strictly full-scale beams, and the number of members is not enough; hence, the size effect obtained in this paper is somewhat limited.

\section{Data Availability}

Some data used to support the findings of this study are included within the article. All datasets generated during the current study are not publicly available since the data also forms part of an ongoing study but are available from the corresponding author upon reasonable request.

\section{Disclosure}

The opinions and findings in this paper are those of authors and do not represent those of sponsors.

\section{Conflicts of Interest}

The authors declare that they have no conflicts of interest regarding the publication of this paper.

\section{Authors' Contributions}

Danping Gao and Bowang Chen contributed equally to this paper.

\section{Acknowledgments}

This research was financially supported by the Transformation of Key Technology Achievement of Modern Hybrid Timber Structure, High-Tech Industry Science and Technology Innovation Leading Plan of Hunan Province of China (2022GK4052). 


\section{References}

[1] Z. H. Jiang, L. Chang, Z. Wang, and L. Gao, "Physical and mechanical properties of glued structural laminated bamboo," China Wood Industry, vol. 35, no. 4, pp. 22-24, 2005.

[2] Y. T. Zhang and L. P. He, "Comparison of mechanical properties of glued laminated bamboo wood and common structural timbers," Journal of Zhejiang A\&F University, vol. 24, no. 1, pp. 100-104, 2007.

[3] M. Mahdavi, P. L. Clouston, and S. R. Arwade, "Development of laminated bamboo lumber: review of processing, performance, and economical considerations," Journal of Materials in Civil Engineering, vol. 23, no. 7, pp. 1036-1042, 2011.

[4] Y. Su, S. J. Zong, D. Xu, D. Q. Sun, and D. S. Huang, "Experimental study on nonlinear bending of glued laminated bamboo beams," Journal of Building Structures, vol. 36, no. 3, pp. 36-43, 2016.

[5] H.-t. Li, J.-w. Su, Q.-s. Zhang, A. J. Deeks, and D. Hui, "Mechanical performance of laminated bamboo column under axial compression," Composites Part B: Engineering, vol. 79, pp. 374-382, 2015.

[6] G. Chen, X. Li, Y. F. Yu, B. He, and L. L. Zhao, "Research on constitutive relationship of flat-pressure laminated bamboo lumber for structural application," Building Structure, vol. 51, no. 2, pp. 135-139, 2021.

[7] C. A. Tang and B. W. Chen, "Experimental study on the longterm compression performance of glue-laminated bamboo under lateral pressure," Journal of Hunan City University, vol. 29, no. 5, pp. 11-13, 2020.

[8] "Members of the State Administration for Market Regulation \& Standardization Administration," Gb/T. 36872-2018 Code of Glued Laminated Timber Production, State Administration for Market Regulation \& Standardization Administration, China, 2018.

[9] "Members of the Manual Drafting Committee," Manual for Design of Timber Structures, China Building Industry Press, China, 2020.

[10] "Members of the State Administration for Market Regulation \& Standardization Administration," GB/T 1929-2009 Method of Sample Logs Sawing and Test Specimens Selection for Physical and Mechanical Tests of Wood, State Administration for Market Regulation \& Standardization Administration, China, 2009.

[11] "Members of the State Administration for Market Regulation \& Standardization Administration," Gb/T. 1938-2009 Method of Testing in Tensile Strength Parallel to Grain of Wood, State Administration for Market Regulation \& Standardization Administration, China, 2009.

[12] "Members of the State Administration for Market Regulation \& Standardization Administration," Gb/T. 1935-2009 Method of Testing in Compressive Strength Parallel to Grain of Wood, State Administration for Market Regulation \& Standardization Administration, China, 2009.

[13] "Members of the State Administration for Market Regulation \& Standardization Administration," Gb/T. 1936.1-2009 Method of Testing in Bending Strength of Wood, State Administration for Market Regulation \& Standardization Administration, China, 2009.

[14] "Members of the State Administration for Market Regulation \& Standardization Administration," Gb/T. 1936.2-2009 Method for Determination of the Modulus of Elasticity in Static Bending of Wood, State Administration for Market Regulation \& Standardization Administration, China, 2009.

[15] "Members of the State Administration for Market Regulation \& Standardization Administration," GB/T 1928-2009 Test
Methods for Physical and Mechanical Properties of Wood, State Administration for Market Regulation \& Standardization Administration, China, 2009.

[16] "Members of the Ministry of Hosing and Urban-Rural Development of the People's Republic of China \& State Administration for Market Regulation," GB 50068-2018 Unified Standard for Reliability Design of Building Structure, Ministry of Hosing and Urban-Rural Development of the People's Republic of China \& State Administration for Market Regulation, China, 2018.

[17] E. C. Zhu, S. Niu, L. Qiao, and J. L. Pan, "Reliability analysis of wood structures and method for determining the design strength value of timber," Journal of Building Structures, vol. 38, no. 2, pp. 28-35, 2017.

[18] "Members of the Ministry of Hosing and Urban-Rural Development of the People's Republic of China \& State Administration for Market Regulation.” GB 50005-2017 Standard for Design of Timber Structures, Ministry of Hosing and Urban-Rural Development of the People's Republic of China \& State Administration for Market Regulation, China, 2017.

[19] M. J. He, Z. Li, and L. J. Wu, "Experimental and analytical investigation into mechanical properties and design parameters of modified scrimber," Journal of Building Structures, vol. 41, no. S1, pp. 364-372, 2020.

[20] Y. Xiao, R. Z. Yang, B. Shan, L. Y. She, and L. Li, "Experimental research on mechanical properties of glubam," Journal of Building Structures, vol. 33, no. 11, pp. 150-157, 2012.

[21] "Members of the Ministry of Hosing and Urban-Rural Development of the People's Republic of China \& State Administration for Market Regulation." Gb/T. 50329-2012 Standard for Test Methods of Timber Structures, Ministry of Hosing and Urban-Rural Development of the People's Republic of China \& State Administration for Market Regulation, China, 2012.

[22] J. L. Pan and E. C. Zhu, Design Principle of Timber Structures, China Building Industry Press, China, 2018.

[23] "Members of the American Society for Testing Material," Establishing Allowable Properties for Visually-Graded Dimension Lumber from In-Grade Tests of Full-Size Specimens, ASTM International, West Conshohocken, PA, ASTM D1990-16 Standard Practice for, 2016.

[24] F. J. Keenan, J. Kryla, and B. Kyokong, "Shear strength of spruce glued-laminated timber beams," Canadian Journal of Civil Engineering, vol. 12, no. 3, pp. 661-672, 1985.

[25] J. Longworth, "Longitudinal shear strength of timber beams," Forest Products Journal, vol. 27, no. 8, pp. 19-23, 1977.

[26] D. R. Rammer and L. A. Soltis, "Experimental Shear Strength of Glued-Laminated Beams," USDA Forest Service. Forest Products Laboratory, Madison, Wis, United States Forest Service Research Paper FPL-GTR-527, 1994.

[27] Members of the American Society for Testing Material, ASTM International, West Conshohocken, PA, ASTM D143-14 Standard Test Methods for Small Clear Specimens of Timber, 2014. 